\title{
Review of the literature and description of a case of Sclerosing Encapsulating Peritonitis requiring home parenteral nutrition
}

\author{
Konstantinos C. Fragkos, ${ }^{*, a, b}$ Faris M. Al-Sulttan, ${ }^{a, b}$ Rajeshwar P. Mookerjee, ${ }^{b, c}$ Alison \\ Winstanley, ${ }^{d}$ Alastair Forbes ${ }^{\mathrm{a}, \mathrm{b}}$ \\ ${ }^{a}$ Centre for Gastroenterology and Nutrition, University College London, London WC1E 6JJ, UK \\ ${ }^{b}$ Gastrointestinal Services, University College Hospital, London NW1 2PG, UK \\ ${ }^{c}$ UCL Institute of Hepatology, UCL Medical School, Royal Free Hospital, London NW3 2QG, UK \\ ${ }^{4}$ Department of Histopathology, University College Hospital, London NW1 2BU, UK
}

Conflict of Interest: None Declared

Correspondence to: Dr Konstantinos C. Fragkos, Clinical Research Fellow, Gastrointestinal Services, University College London Hospitals, London NW1 2PG, UK, e-mail: constantinos.frangos.09@ucl.ac.uk, Tel. +447960340489, Fax: +442073809218

Note: This article was published in Zeitschrift für Gastroenterologie. The copyright remains with the publisher (Georg Thieme Verlag KG) and is available at https://www.thieme-connect.com/DOI/DOI?10.1055/s-00311281847. The full citation is:

Fragkos KC, Al-Sulttan FM, Mookerjee RP, Winstanley A, Forbes A. Review of the literature and description of a case of sclerosing encapsulating peritonitis requiring home parenteral nutrition. Z Gastroenterol. 2011 Jul;49(12):1543-8. doi: 10.1055/s-0031-1281847

\begin{abstract}
We present a case of a 48 year old HIV patient, who had recurrent episodes of ascites since 2007. His history includes ischaemic heart disease, for which he was treated with atenolol from 2005 to 2007, and Type 2 diabetes; he was later started on propranolol 40mg twice a day from 2007 for Didanosine-induced portal hypertension. Because of negative cultures and neutrophil count $<250$ cells $/ \mu \mathrm{L}$, spontaneous bacterial peritonitis was excluded. However, some low grade-peritoneal irritation cannot be ruled out because his CRP varied from 24 to 258, during 2007-2009, without any other obvious inflammatory cause. He was finally diagnosed in July 2009 with sclerosing encapsulating peritonitis (SEP) based on clinical features of intestinal obstruction, histology and imaging, including computed tomography and magnetic resonance imaging. Propranolol was stopped in November 2009. Because of the patient's severe intestinal obstruction, he was started on parenteral nutrition $2 \mathrm{~L} /$ day. Since then, his CRP has returned to normal levels and there is a great improvement of his clinical features. This case demonstrates beta-blockers as a potential cause of SEP, while the presence of some low-grade peritoneal inflammation leading to SEP is also very likely.
\end{abstract}

Keywords: sclerosing encapsulating peritonitis, beta-blockers, ascites, parenteral nutrition

\footnotetext{
* This author's name is also written as Constantinos C. Frangos
} 


\title{
Durchsicht der Literatur und Fallbericht eines Patienten mit sklerosierender verkapselnder Peritonitis, der durch parenterale Ernährung zu Hause versorgt wird
}

\begin{abstract}
Zusammenfassung
Wir präsentieren den Fall eines 48-jährigen HIV Patienten, der seit 2007 an periodisch auftretendem Aszites leidet. Seine Krankengeschichte beinhaltet zudem eine ischaemische Herzerkrankung, die von 2005 bis 2007 mit Atenolol behandelt wurde, und Typ-2-Diabetes; später im Jahr 2007 begann man aufgrund einer durch Didanosin herbeigeführte Portalen Hypertension, ihm zweimal täglich $40 \mathrm{mg}$ Propanolol zu verabreichen. Aufgrund negativer Blutkulturen und einer Neutrophilenzahl $<250 / \mu \mathrm{l}$ wurde eine Spontan bakterielle Peritonitis ausgeschlossen. Allerdings kann eine leichte Peritoneale Irritation nicht ausgeschlossen werden, da sein CRP von 2007- 2009 ohne jegliche andere offensichtliche Entzündungsursache zwischen 24 und 258 schwankte. Schließlich wurde bei ihm im Juli 2009 eine sklerosierende verkapselnde Peritonitis (SEP) diagnostiziert, basierend auf klinischen Merkmalen eines Darmverschlusses, Histologie und Bildgebung, einschließlich einer Computer-Tomographie und einer Magnetresonanz-Tomographie. Propanolol wurde im November 2009 abgesetzt. Aufgrund des schwerwiegenden Darmverschlusses wurde beim Patienten 2l/Tag parenterale Ernährung angesetzt. Seitdem befindet sich sein CRP wieder auf normalem Niveau und seine klinischen Merkmale haben sich enorm verbessert. Dieser Fall zeigt, dass Beta-Blocker eine potentielle Ursache für SEP darstellen, jedoch gleichzeitig nicht ausgeschlossen werden kann, dass das Vorhandensein einer leichten peritonealen Entzündung zu einer SEP führt.
\end{abstract}

Schlüsselwörter: Sklerosierende verkapselnde Peritonitis, Beta-Blocker, Aszites, parenterale Ernährung 


\section{Review of the literature and description of a case of Sclerosing Encapsulating Peritonitis requiring home parenteral nutrition}

\section{Introduction}

Peritonitis is still considered to be a disease with high morbidity and mortality, despite the increase of knowledge in the pathophysiology of it. Sclerosing Encapsulating Peritonitis (SEP) is a severe kind of peritonitis, relatively frequent in subjects submitted to peritoneal dialysis during the last 5 years [1-2]; other causes of the disease are shown in Table 1 [2].

Table 1. Classification of SEP.[2]

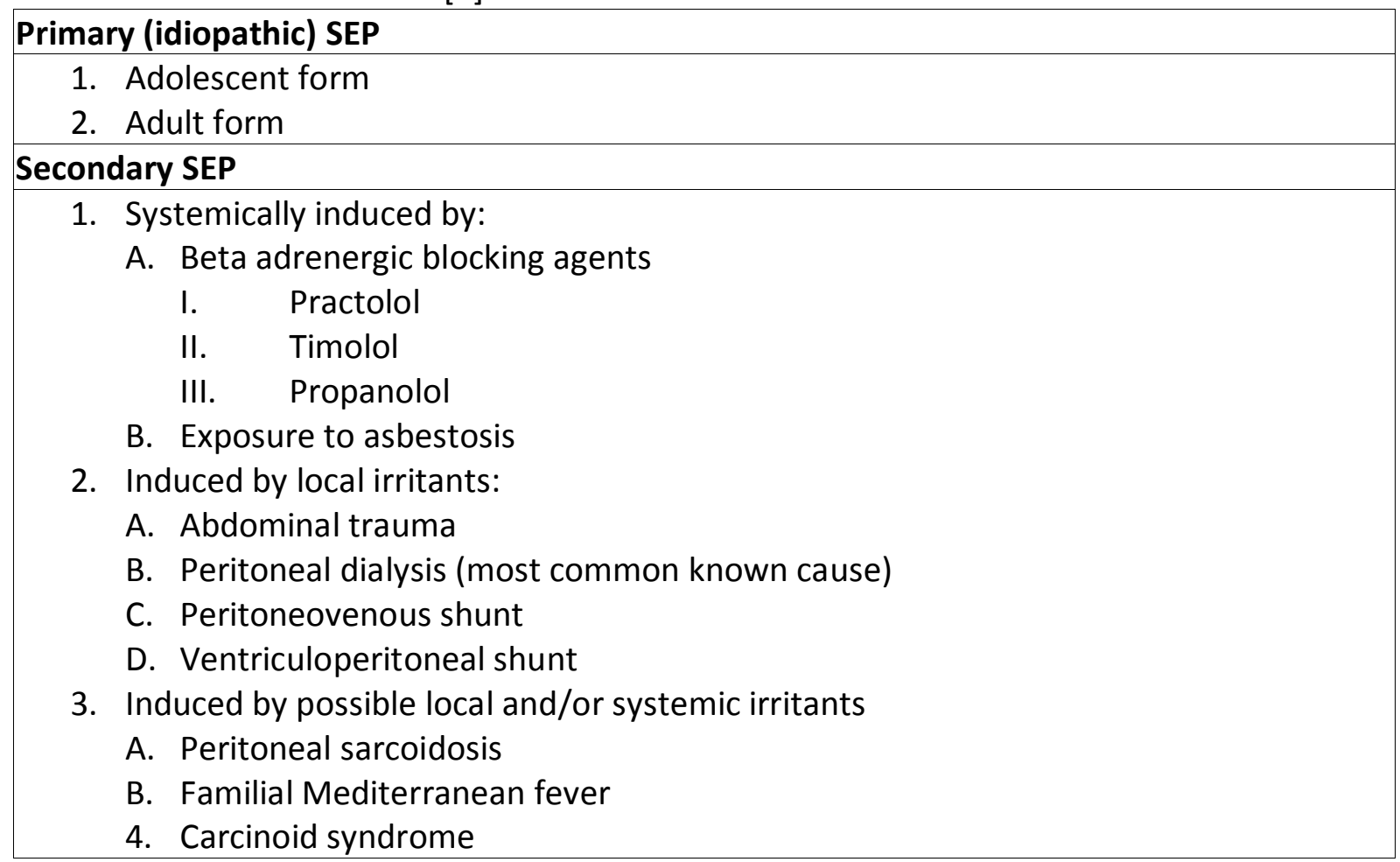

SEP is a rare cause of intestinal obstruction that is characterized by a thick, white, fibrous membrane formation in the peritoneum that partially or completely encases the bowel loops (abdominal cocoon) [3]. Its treatment involves surgery for dealing with the obstruction, administering steroids and immunosuppressants, while there are only few cases describing the use of total parenteral nutrition (TPN) given as therapy for the management of SEP have been described (Kawanishi, many articles, Rajani) [4-5].

We present a case and review the literature of SEP associated with spontaneous bacterial peritonitis, beta blocker use (propranolol and atenolol), discussing the presentation, aetiology and management of this rare condition, by signifying the benefits of parenteral nutrition along with their standard treatment.

\section{Case Report}

This 48-year old patient presented to our hospital in August 2007 for investigation of ascites, noted at emergency laparotomy earlier in June 2007 (for incarcerated umbilical hernia). He 
has a history of ischaemic heart disease (myocardial infarction and 2 angioplasties in 2006), treated with atenolol from 2005 to 2007, diabetes and HIV infection since 1999, treated with Highly Active Anti-Retroviral Therapy (HAART). He was on Didanosine (DDI) until April 2007, which was then stopped. He was treated with an initial ascitic tap which was negative for spontaneous bacterial peritonitis (SBP), and was a transudate with neutrophil count less than $250 / \mathrm{ml}$. Gram stain and mycobacterial cultures were negative on more than one occasion; bone marrow stain and culture for acid fast bacilli were also negative. Autoantibody screening for $\mathrm{HepB}, \mathrm{HepC}, \mathrm{HHV}-8$, and autoimmune diseases were all negative. There was no evidence of heart failure evident on ultrasound (2009) or history of alcohol misuse. Then he went to have an ultrasound guided ascitic drain (3.5L removed) and ultrasound guided liver biopsy.

The liver biopsy showed probable cirrhosis but a nodular regenerative hyperplasia could not be excluded. Macrophages with lipofuscin were seen and this would imply that, whatever the agent causing the cirrhosis, this had been withdrawn. So DDI-induced liver damage was put as a diagnosis. On the same admission he had an Oesophageal-Gastroduodenal endoscopy which showed 3 barely noticeable oesophageal varices, 2 shallow gastric ulcers, portal hypertensive gastropathy and duodenitis. He was prescribed spironolactone for the ascites and discharged. Other medications prescribed were Aspirin, Pravastatin, Ranitidine, and Propranolol 40mg bd. Because of painful gynaecomastia, spironolactone was switched to Amiloride in January 2008.

In April 2008, his ultrasound showed an abnormal echotexture in the liver and splenomegaly. In June 2008, he went to have another liver biopsy, which demonstrated moderate to severe fibrosis but was not reported as being consistent with nodular regenerative hyperplasia.

In January 2009, he was noted having ongoing problems with recurring ascites in spite of being on Amiloride; for that reason he was considered to be a potential candidate for pretransplant assessment since his CD4 had been relatively acceptable and his HIV viral load was always very low or undetectable in some instances. Also, his propranolol was changed to atenolol.

In February 2009, abdominal computed tomography (CT) images confirmed ascites and an enlarged spleen as well as an irregular lesion in the left lobe of his liver and one in the right lobe of his liver. These were thought to be non-specific findings and it was not felt that he would need any course of investigation or treatment at that time. His recurring episodes of ascites continued to be challenging so he was changed from Amiloride to Furosemide. Because of failure to control his ascites, in May 2009 he was given a combination of Spironolactone $100 \mathrm{mg}$ once a day plus $40 \mathrm{mg}$ of Furosemide once a day.

On 20 May 2009, the patient was admitted with abdominal pain and distention of 12 hours duration prior to admission; due to his history of cirrhosis this was attributed to ascites and $3 \mathrm{~L}$ were drained. The pain however continued to be a problem after drainage and an abdominal x-ray showed dilated loops of small bowel; at that time he was passing flatus and faeces throughout his admission and never showed any signs of peritonitis. Although his white cell count was normal, his CRP was around 80 and an inflammatory or infective cause of his small bowel pathology was suspected (Figure 1). Colonoscopy was performed which unfortunately could not reach the site of subacute obstruction in order to perform a terminal ileum biopsy. Due to the patient's history of ascites, elective laparoscopic surgery was not recommended due to the possibility of fistula formation with presence of ascites. In May-June 2009, CT and Magnetic Resonance Imaging (MRI) showed evidence of mechanical obstruction (Figure 2 and 3). The proximal small bowel was dilated down to a "mass" of 
collapsed loops within the right iliac fossa involving the terminal ileum. The morphology of this collapsed section was unchanged over the last 3 weeks and therefore suspicious of a fixed band. The peristalsis views showed no real evidence of movement within the collapsed segment. The dilated loops were oedematous. In July 2009 his renal function seemed to decline and continued to have recurrent episodes of abdominal pain, distention, and vomiting. Because of these episodes, he was admitted in July 2009 and discharged in November 2009. In July 2009, he had complete bowel obstruction which necessitated surgical laparotomy. Adhesiolysis was performed by dissecting fibrous tissue releasing the small bowel attached to the peritoneum, without any bowel resection. On inspection a thick white fibrous layer was noted (abdominal cocoon) and peritoneal biopsy showed dense hyaline fibrosis and chronic inflammation with no granulomas and no suggestive features of tuberculosis; no small bowel biopsy was taken at that stage. He was finally diagnosed with SEP, based on previous CT and MRI images, clinical and laparotomy features. On his discharge, beta-blocker use was permanently stopped.

For his small bowel obstruction, nasogastric (NG) tube aspirations were attempted but he could not tolerate NG feeding, due to persistent abdominal pain post-feeding in the presence of chronic sub-acute bowel obstruction. Therefore he was started on daily parenteral nutrition 1.5L/day in September 2009. His prescription was Nitrogen 11.4g, Glucose $800 \mathrm{Kcal}$, Lipid 550kcal, Sodium $100 \mathrm{mmol}$, Potassium $20 \mathrm{mmol}$, Calcium $5 \mathrm{mmol}$, Magnesium 5mmol, Phosphate $17 \mathrm{mmol}$, Trace Elements-Additrace ${ }^{\circledR} 1$ vial and VitaminsCernevit ${ }^{\circledR} 1$ vial, compounded in a multilayer bag. His subsequent subscriptions are shown in Table 1. He suffers from episodes of hyperkalaemia (reaching $6.4 \mathrm{mmol} / \mathrm{L}$ ), precipitated by spironolactone use, renal impairment and parenteral nutrition with potassium, thus needing regular adjustments. Today we have managed to reduce his daily PN to 1.5L/day.

Since the treatment of his intestinal obstruction and the initiation of parenteral nutrition, his CRP levels have greatly decreased to normal (last CRP in 2011 was $3 \mathrm{mg} / \mathrm{L}$ ), compare to previous levels around 90. At present he is on home parenteral nutrition with a Hickman-line inserted. He was started on prednisolone for SEP but no dramatic effect has yet been seen.

Table 2. Home Parenteral Nutrition Prescriptions

\begin{tabular}{|c|c|c|c|c|c|c|c|}
\hline \multirow[t]{2}{*}{ Ingredients } & \multicolumn{7}{|c|}{ Date } \\
\hline & $25 / 10 / 09$ & $3 / 11 / 09$ & $7 / 4 / 10$ & $24 / 5 / 2010$ & $14 / 09 / 10$ & $27 / 1 / 2011$ & $4 / 7 / 11$ \\
\hline Total Volume (ml) & 1500 & 1600 & 1550 & 1500 & 1500 & 1500 & 1500 \\
\hline Nitrogen(g) & 11.4 & 12.85 & 12.85 & 8.25 & 9 & 9 & 8.25 \\
\hline Glucose (Kcal) & 800 & 1000 & 800 & 800 & 800 & 800 & 800 \\
\hline Lipid (Kcal) & 550 & 650 & 550 & 550 & 500 & 500 & 500 \\
\hline Sodium (mmol) & 100 & 100 & 100 & 100 & 30 & 50 & 50 \\
\hline Potassium (mmol) & 20 & 0 & 20 & 0 & 20 & 10 & 10 \\
\hline Calcium (mmol) & 5 & 5 & 5 & 5 & 5 & 5 & 5 \\
\hline Magnesium (mmol) & 5 & 5 & 5 & 5 & 5 & 5 & 5 \\
\hline Phosphate (mmol) & 17 & 17 & 17 & 17 & 17 & 17 & 17 \\
\hline $\begin{array}{l}\text { Trace Elements } \\
\text { Additrace (vials) }\end{array}$ & 1 & 1 & 1 & 1 & 1 & 1 & 1 \\
\hline $\begin{array}{l}\text { Vitamins Cernevit } \\
\text { (vials) }\end{array}$ & 1 & 1 & 1 & 1 & 1 & 1 & 1 \\
\hline
\end{tabular}

Daily infusion compounded in multilayer bag 


\section{Discussion}

SEP, first described in 1907 [6], is a rare cause of intestinal obstruction caused by thick white fibrous tissue formation in the peritoneum that encase and subsequently cause partial or complete intestinal obstruction (abdominal cocoon syndrome). The most common identified cause of this rare condition is continuous ambulatory peritoneal dialysis but other causes like beta blockers could be a cause as well (Table 1) [7-8]. Other associations reported in the literature include ovarian thecomas, tuberculous pelvic inflammatory disease, ventriculoperitonealshunts, systemic lupus erythematosus, orthotopic liver transplantation, protein $S$ deficiency, ovarian cysts, keratoconjunctivitis sicca syndrome and various beta adrenergic blocking agents [3, 5, 9-13].

The pathogenesis of SEP is not fully understood, but it is believed that chronic peritoneal irritation by agents that cause serositis or previous episodes of peritonitis results in mesothelial cell loss which leads to fibrous fibroneogenesis, which is the hall mark of SEP [5, 14]. It is suggested that it goes through three phases: an initial inflammatory stage with eleveated CRP, followed by the encapsulating stage with the appearance of ileus and the ileus stage where bowel obstruction progresses (Kawanishi 2005). The exact mechanism by which beta blockers induce sclerosing peritonitis is unknown, but two suggested hypotheses include a possible allergic type reaction to the class of drug or perhaps an excess production of intraperitoneal collagen, which has been shown to be induced by these agents $[2,14]$. Several theories tried to explain this condition: when it was first described in adolescent girls from tropical and subtropical countries, this suggested retrograde menstruation as a cause [15], or retrograde viral infection via fallopian tubes [16], but appearance of the disease in males and older ages groups discards this hypothesis [17-18].

The presentation of SEP can be quite challenging ranging from abdominal pain, nausea, vomiting and vague symptoms to frank intestinal obstruction, most of the symptoms being related to partial small bowel obstruction. SEP can also present with recurrent ascites or as an abdominal mass. Although the diagnosis is most commonly made at laparotomy, occasionally it is suspected on radiological imaging [19]. On CT scan, SEP can appear as peritoneal thickening or calcification, loculated fluid collections or matting of the small bowel. Thickening of the small bowel loops and calcifications of the liver capsule, spleen, posterior peritoneal wall or bowel can also be seen [20]. Ultrasound and magnetic resonance imaging have also been useful in making this diagnosis [19].

Our patient developed SEP in the absence of peritoneal dialysis and did not seem to have any of the previous conditions linked to SEP. However, he was on different beta blockers (propranolol and atenolol) from 2005 and none of his other medications seem to be linked to SEP. He was also on anti-retroviral medication, but there doesn't seem to be any causative link with the pathogenesis of SEP (Rivera 2007, Mesquita 2007). So his use of betablockers seems to be a possible cause of the SEP, which is consistent with the literature [3]. The classic beta blocker that was associated with SEP is practolol in 1974 [13], being withdrawn from the market in 1975. Since then many case reported with other beta blockers like atenolol propranolol, timolol, metoprolol and sotalol [3, 21]. Karla et al. [3] described 2 patients who were receiving propranolol for 2 years and 2 months respectively and both developed SEP. Their doses were $320 \mathrm{mg}$ and $80 \mathrm{mg}$ day, showing that the development of SEP is independent of the dose. Both patients recovered.

Another cause we believe could lead to SEP is the presence of culture negative, neutrophil negative low-grade inflammatory peritoneal irritation. Although the patient was never diagnosed with spontaneous bacterial peritonitis (SBP) in terms of standard criteria, he 
constantly presented with high CRP for which the cause could not be identified (Kawanaishi $2005,2002)$. We believe that there was some very low grade inflammatory process in the ascitic fluid which finally led to SEP (peritoneal irritation). Evans et al. [22] noted that about half of his patients with SBP $(n=15)$ from his cohort of patients with cirrhotic ascites $(n=427)$, had culture negative neutrocytic ascites, as described by Runyon and Hoefs [23]. This low grade inflammation could be associated with development of serositis leading inevitably to sclerosing peritonitis [5]. SEP after SBP was also reported in a 36-year old woman 3 weeks after she delivered her baby [24]. A recent meta-analysis showed that studies use various cut-off points for ascetic neutrophil count ( $>500$ or $>250$ cell $/ \mu \mathrm{L}$ ). The most accurate parameters to diagnose SBP were an ascitic neutrophil count of greater than $500 \mathrm{cells} / \mu \mathrm{L}$ (summary LR, 10.6; 95\% Cl, 6.1-18.3), even though antibiotics are usually started when neutrophils are greater than 250 cells/ $\mu \mathrm{L}$. Although an ascitic neutrophil count of 250 cells $/ \mu \mathrm{L}$ or less lowers the likelihood of SBP (summary LR, $0.20 ; 95 \% \mathrm{Cl}, 0.11-0.37$ ), this is not zero [25].

The next original point in our case is the improvement of our patient's overall condition since he went on parenteral nutrition (PN) from August 2009. Taking into account the worse nutritional state by a medical history of 2 years with ascites, probable cirrhosis and mild to severe systemic inflammation of unknown origin, aggravated by a subileus/ ileus with abdominal pain, distension and vomiting over a period of 3 months, PN expectably has a positive effect on the outcome of the patient and his course of disease. This coincides with the treatment of his intestinal obstruction which most possibly lowered his CRP levels to normal. His CRP levels have gone markedly down to normal and have remained stable over the last year. There is a possibility that certain PN nutrients are lowering his CRP, although this seems initially unlikely.. Few papers discuss the importance of prescribing PN in the treatment of SEP (4,5, Rajani, Kawanishi, urian). Two cases highlight the importance PN: one in a patient who had renal failure and was receiving CAPD for more than 3 years [4] and one in a woman with associated ovarian cysts and kerato-conjunctivitis sicca syndrome [5]. The first patient suffered from intestinal failure associated with obstruction episodes and small bowel resection (Pusateri), while the second suffered predominantly from obstruction related intestinal failure. Kawanishi notes the importance of treating the encapsulating stage of SEP with TPN, which relieves the intestine from the obstruction episodes.

The treatment of SEP is mainly surgical with lysis of the adhesions at laparotomy. A retrospective analysis of 32 patients with this condition as done to determine the best surgical management comparing membrane resection, enterolysis, partial excision of the membrane, intestinal resection and exploratory laparotomy only. Membrane resection resulted in less patients having persistent bowel obstruction or death and the study recommended this be attempted when feasible. No surgical treatment was recommended in cases of associated ascites, asymptomatic sclerosing peritonitis, or sub-acute intestinal obstruction $[2-3,26]$.

\section{Acknowledgments}

This work was undertaken at UCL/UCLH, which receives funding from the Department of Health's NIHR as a Comprehensive Biomedical Research Centre. We also thank Christina Brückner of UCL Language Sciences for helping in the writing of the German abstract. 


\section{References}

${ }^{1}$ Minutolo V, Gagliano G, Angirillo G, et al. Intestinal obstruction due to idiopathic sclerosing encapsulating peritonitis. Clinical report and review of literature. G Chir 2008; 29: 173-176

${ }^{2}$ Cohen O, Abrahamson J, Ben-Ari J, et al. Sclerosing encapsulating peritonitis: Primary and Secondary Forms. J Clin Gastroenterol 1996; 22: 54-57

${ }^{3}$ Kalra S, Atia A, McKinney J, et al. Sclerosing encapsulating peritonitis associated with propranolol usage: a case report and review of the literature. J Dig Dis 2009; 10: 332-335

${ }^{4}$ Pusateri R, Ross R, Marshall R, et al. Sclerosing encapsulating peritonitis: report of a case with small bowel obstruction managed by long-term home parenteral hyperalimentation, and a review of the literature. Am J Kidney Dis 1986; 8: 56-60

${ }^{5}$ Koak Y, Gertner D, Forbes A, et al. Idiopathic sclerosing peritonitis. Eur J Gastroenterol Hepatol 2008; 20: 148-150

${ }^{6}$ Owtschinnikow P. Peritonitis chronica fibrosa incapsulata. Arch Klin Chir 1907; 83: 623-634

${ }^{7}$ Bradley JA, McWhinnie DL, Hamilton DN, et al. Sclerosing obstructive peritonitis after continuous ambulatory peritoneal dialysis. Lancet 1983; 2: 113-114

${ }^{8}$ Hauglustaine D, van Meerbeek J, Monballyu J, et al. Sclerosing peritonitis with mural bowel fibrosis in a patient on long-term CAPD. Clin Nephrol 1984; 22: 158-162

${ }^{9}$ Lalloo S, Krishna D, Maharajh J. Abdominal cocoon associated with tuberculous pelvic inflammatory disease. Br J Radiol 2002; 75: 174-176

10 Maguire D, Srinivasan P, O'Grady J, et al. Sclerosing encapsulating peritonitis after orthotopic liver transplantation. Am J Surg 2001; 182: 151-154

${ }^{11}$ Sigaroudinia MO, Baillie C, Ahmed S, et al. Sclerosing encapsulating peritonitis--a rare complication of ventriculoperitoneal shunts. J Pediatr Surg 2008; 43: E31-33

${ }^{12}$ Sillero JM, Calvet X, Musulen E, et al. Idiopathic pylephlebitis and idiopathic sclerosing peritonitis in a man with protein S deficiency. J Clin Gastroenterol 2001; 32: 262-265

${ }^{13}$ Brown $\mathrm{P}$, Baddeley $\mathrm{H}$, Read $\mathrm{AE}$, et al. Sclerosing peritonitis, an unusual reaction to a $\beta$ adrenergic-blocking drug (practolol). Lancet 1974; 2: 1477-1481

${ }^{14}$ Dobbie JW. Pathogenesis of peritoneal fibrosing syndromes (sclerosing peritonitis) in peritoneal dialysis. Perit Dial Int 1992; 12: 14-27

${ }^{15}$ Eltringham WK, Espiner HJ, Windsor CWO, et al. Sclerosing peritonitis due to practolol: A report on 9 cases and their surgical management. Br J Surg 1977; 64: 229-235

${ }^{16}$ Sieck JO, Cowgill R, Larkworthy W. Peritoneal encapsulation and abdominal cocoon. Case reports and a review of the literature. Gastroenterology 1983; 84: 1597-1601

${ }^{17}$ Masuda C, Fujii Y, Kamiya T, et al. Idiopathic sclerosing peritonitis in a man. Intern Med 1993; 32: 552-555

18 Burstein M, Galun E, Ben-Chetrit E. Idiopathic sclerosing peritonitis in a man. J Clin Gastroenterol 1990; 12: 698-701

${ }^{19} \mathrm{Xu} \mathrm{P}$, Chen LH, Li YM. Idiopathic sclerosing encapsulating peritonitis (or abdominal cocoon): a report of 5 cases. World J Gastroenterol 2007; 13: 3649-3651

${ }^{20}$ George C, Al-Zwae K, Nair S, et al. Computed tomography appearances of sclerosing encapsulating peritonitis. Clin Radiol 2007; 62: 732-737

${ }^{21}$ Johnson DW, Cho Y, Livingston BE, et al. Encapsulating peritoneal sclerosis: incidence, predictors, and outcomes. Kidney Int 2010; 77: 904-912

${ }^{22}$ Evans LT, Kim WR, Poterucha JJ, et al. Spontaneous bacterial peritonitis in asymptomatic outpatients with cirrhotic ascites. Hepatology 2003; 37: 897-901

${ }^{23}$ Runyon BA, Hoefs JC. Culture-negative neutrocytic ascites: a variant of spontaneous bacterial peritonitis. Hepatology 1984; 4: 1209-1211 
${ }^{24}$ Leport J, Devars Du Mayne JF, Hay JM, et al. Chylous ascites and encapsulating peritonitis: unusual complications of spontaneous bacterial peritonitis. Am J Gastroenterol 1987; 82: 463-466

${ }^{25}$ Wong CL, Holroyd-Leduc J, Thorpe KE, et al. Does This Patient Have Bacterial Peritonitis or Portal Hypertension? How Do I Perform a Paracentesis and Analyze the Results? JAMA 2008; 299: 1166-1178

${ }^{26}$ Lo WK, Kawanishi H. Encapsulating peritoneal sclerosis--medical and surgical treatment. Perit Dial Int 2009; 29 Suppl 2: S211-214 


\section{Figures}

Figure 1. A. Blood Markers of the patient. The time point where PN was introduced is shown. B. Additional Blood Markers
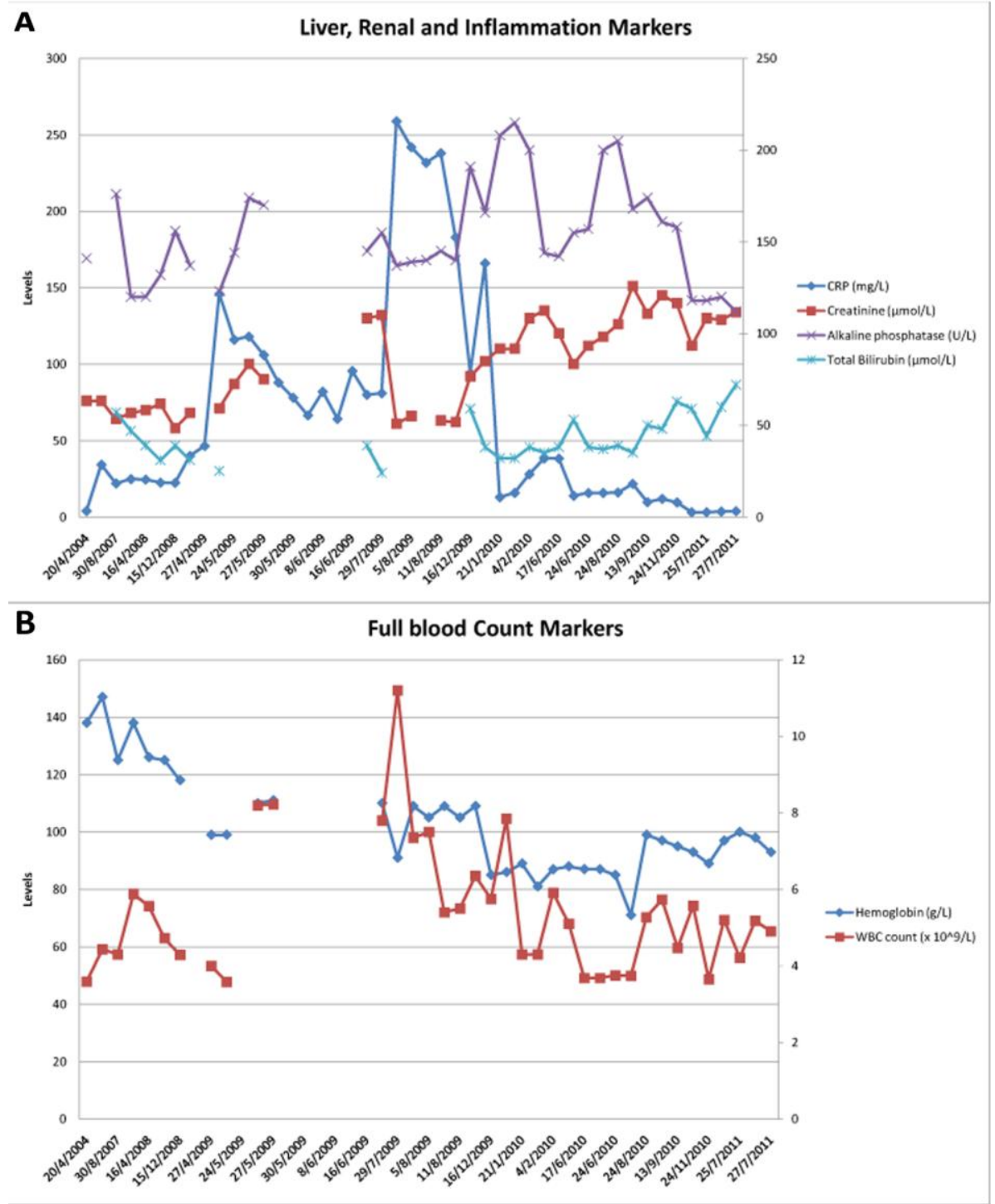

C

Albumin alterations over time

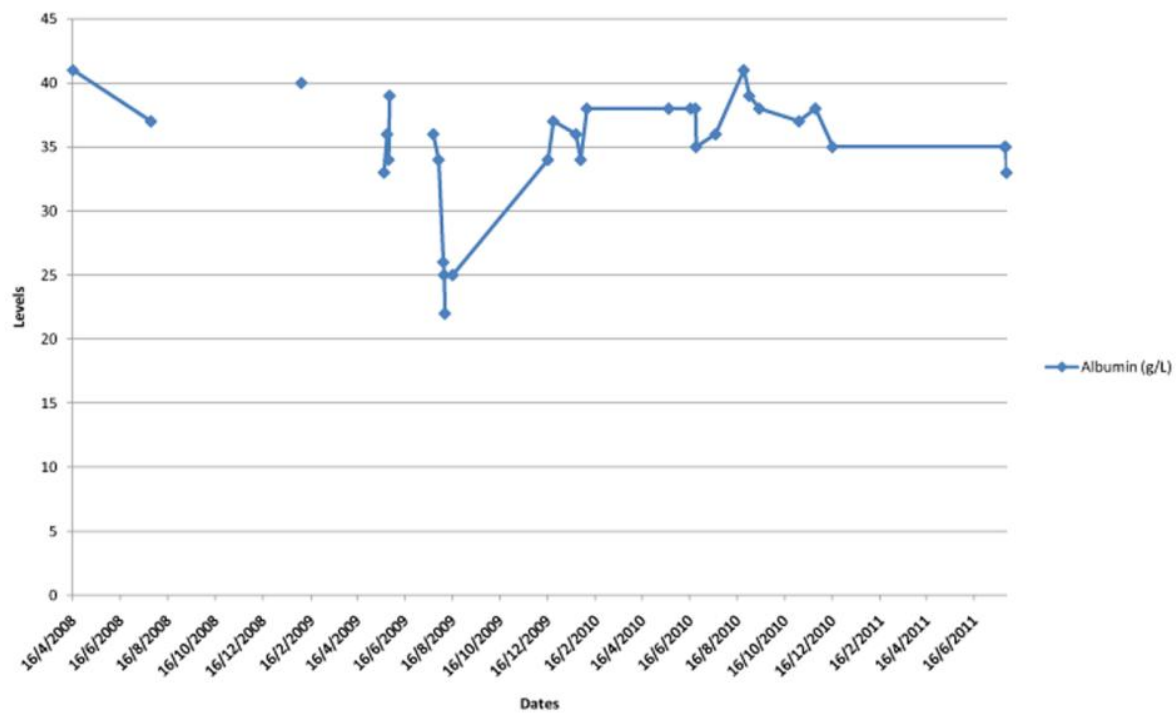


Figure 2. CT scans showing the encapsulated bowel mass and fibrotic peritoneum
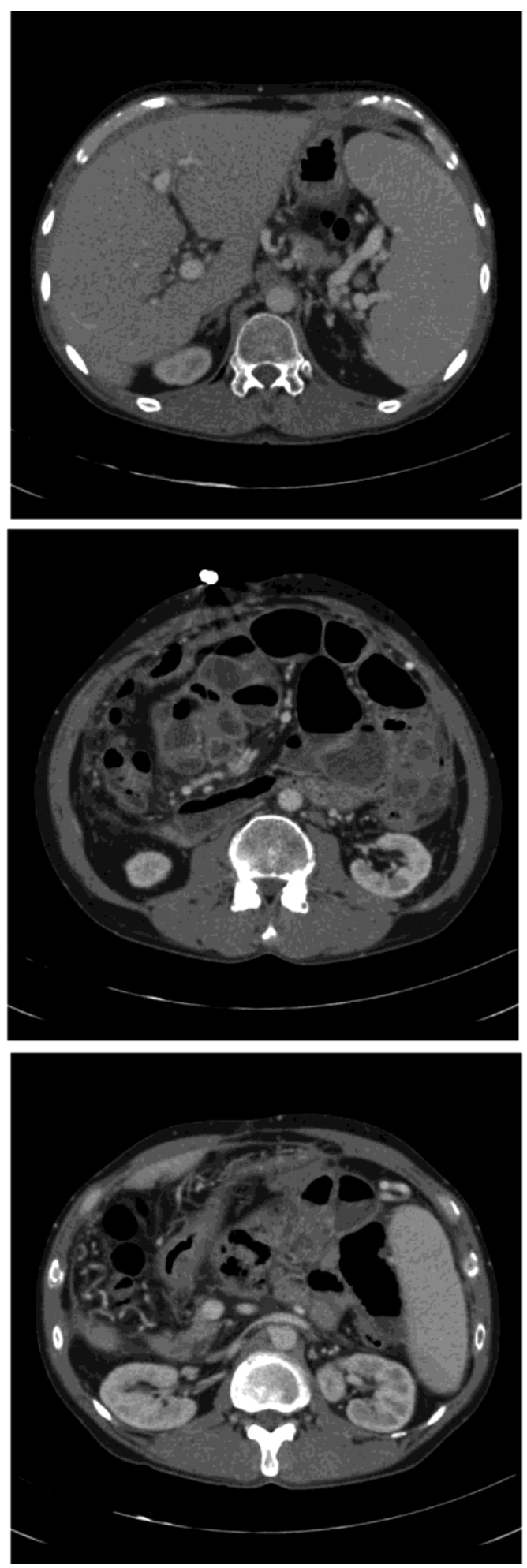

Figure 3. MRI scans showing the encapsulated bowel mass and fibrotic peritoneum
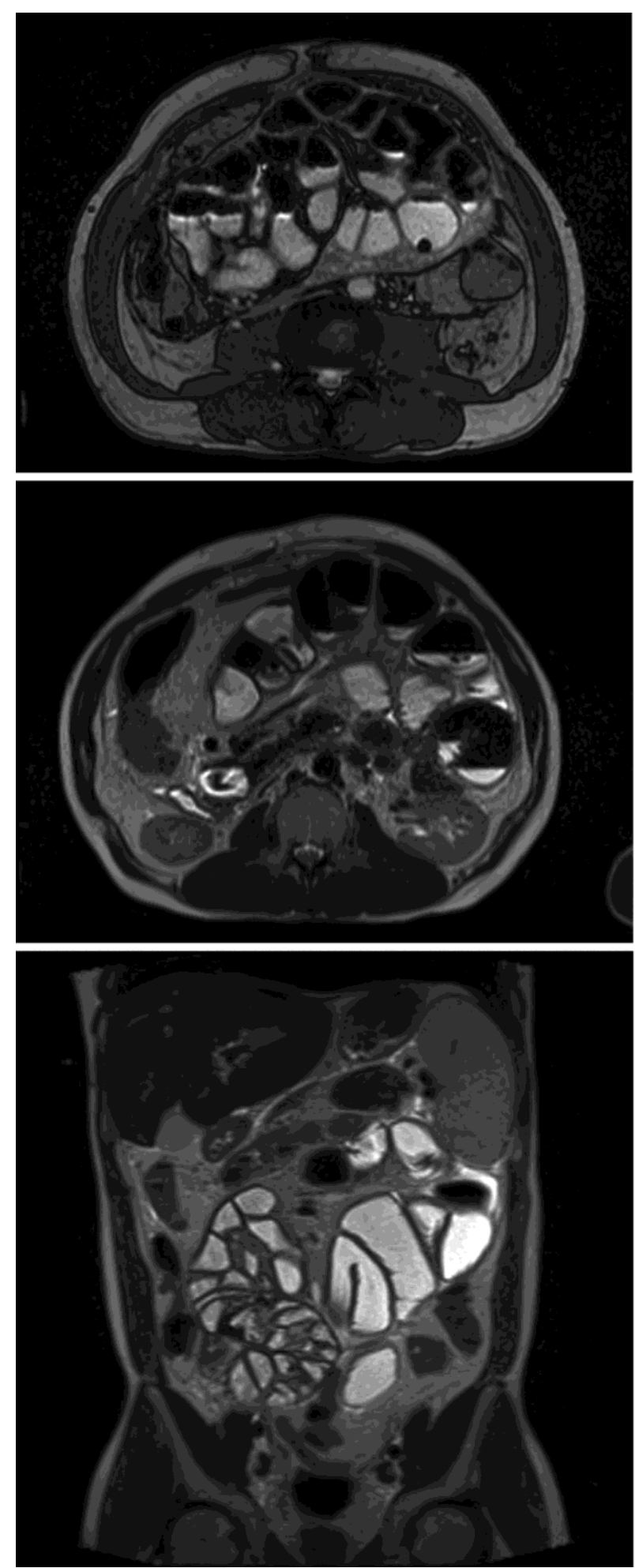